\title{
Exercise therapy, patient education, and patellar taping in the treatment of adolescents with patellofemoral pain: a prospective pilot study with 6 months follow-up
}

Michael S. Rathleff ${ }^{1,2^{*}}$, Camilla R. Rathleff ${ }^{2}$, Sinead Holden ${ }^{1}$, Kristian Thorborg ${ }^{3}$ and Jens L. Olesen ${ }^{1,4}$

\begin{abstract}
Background: Patellofemoral pain (PFP) is the most common knee condition among adolescents, with a prevalence of $6-7 \%$ resulting in reduced function and quality of life. Exercise therapy is recommended for treating PFP, but has only been tested in older adolescents (15-19 years). This pilot study aimed to investigate the adherence to, and clinical effects of, exercise and patient education in young adolescents (12-16 years), with PFP.

Methods: Twenty adolescents (16 females) with PFP were recruited from a population-based cohort to undergo a 3-month multimodal intervention. This comprised of a 30-min patient education and group-based exercise therapy. Exercises included supervised lower extremity strength exercises three times per week, in addition to similar home-based strength exercises. Outcomes included a 7-point global rating of change scale (ranging from "completely recovered" to "worse than ever"), the Knee injury and Osteoarthritis Outcome Score (KOOS), physical activity scale (PAS), weekly sports participation and health-related quality of life measured by European Quality of Life 5 dimensions Youth (EQ-5DY) and isometric knee and hip muscle strength. Pain was measured on a visual analogue scale (VAS), and satisfaction treatment was measured on a five-point Likert scale ranging from "highly satisfied" to "not satisfied at all". These were collected at 3- and 6-month follow-ups. Adherence to supervised exercise was measured as session attendance, and adolescent self-reported adherence to home-based exercises.
\end{abstract}

Results: Adherence to the exercise therapy was poor, with adolescents participating in a median of 16 (IQR 5.5-25) out of 39 possible supervised training session. Five out of 18 adolescents had a successful outcome after both 3 and 6 months. There were no relevant changes in isometric muscle strength.

Conclusion: This was the first study to investigate adherence to, and clinical effects of, exercise therapy and patient education in young adolescents with patellofemoral pain. Adherence to the exercise therapy was low with little to no clinical effects making a full clinical trial impractical. Future studies need to explore how an intervention can be successfully tailored to young adolescents with patellofemoral pain to obtain good adherence while improving pain and function.

\footnotetext{
* Correspondence: misr@hst.aau.dk

${ }^{1}$ Research Unit for General Practice, Department of Clinical Medicine, Aalborg

University, Aalborg, Denmark

2Department of Occupational Therapy and Physiotherapy, Department of

Clinical Medicine, Aalborg University Hospital, Aalborg, Denmark

Full list of author information is available at the end of the article
} 


\section{Background}

There is an 8-fold increase in the number of general practice consultations for knee problems between the ages of 5-9 and 10-19 [1, 2]. Patellofemoral pain (PFP) is the most common knee complaint, affecting $6-7 \%$ of adolescents [3, 4]. PFP is characterised by diffuse anterior knee pain, which is provoked by squatting, prolonged sitting, and stairclimbing [5]. Pain can often be longstanding, which will impact function and health-related quality of life [5].

Exercise therapy is one of the foundations for treating PFP, being recommended by both a Cochrane review and expert consensus [6, 7]. A previous cluster randomised trial in older adolescents (15-19 years of age) with PFP, demonstrated that the addition of exercise therapy to patient education improved recovery in the short(3 months), and long-term (24 months) [8]. However, the recovery rate was lower than what has previously been observed among adults, with only one-third being recovered at follow-up [9].

Adolescents with PFP in this study by Rathleff et al. [8] already had a symptom duration of more than 3 years, with only $5 \%$ reporting a symptom duration less than 6 months. This symptom duration is longer than in previous trials on adults. van Linschoten et al. [8] reported that the majority (nearly 68\%) of patients in their trial had symptoms for 2-6 months, while the median symptom duration reported by Collins et al. [9] was 28 months, with only $25 \%$ having symptoms for less than 12 months. This is important, because previous studies show that longer symptom duration is associated with a poorer outcome after treatment [10]. The differences in symptom duration between adolescents and adults may explain the lower overall effect observed in adolescents by Rathleff et al. [9]. If true, then perhaps the efficacy of exercise therapy in adolescents can be increased by targeting younger adolescents with a shorter symptom duration. No studies have investigated the delivery of supervised exercise to younger adolescents with PFP.

Therefore, the purpose of this pilot study was to investigate the adherence to, and effect of an exercise therapy intervention, on a self-reported Global Rating of Change (GROC), knee function (KOOS) and muscle strength in young adolescents with PFP (12-16 years of age). Specifically, the aim was to explore adherence to exercise therapy and to use the patient reported outcomes to inform a sample size calculation for a definitive trial.

\section{Methods}

\section{Study design}

This study was designed as a cohort study, including 20 adolescents with PFP. Participants were recruited from a population-based cohort (Adolescent Pain in Aalborg 2011, the APA2011-cohort) [11]. The reporting of the study complies with the STROBE reporting guideline and the TIDieR checklist for reporting of interventions $[12,13]$.

\section{Recruitment}

In September 2011, eight lower secondary schools in Aalborg were invited to answer an online questionnaire and to be part of the Adolescent Pain in Aalborg 2001 (APA2011)-cohort. A total of 768 students aged 12-15 years answered the online questionnaire, with 215 (28\%) reporting knee pain. Those reporting knee pain were contacted in September 2012. They were offered a clinical examination by an experienced rheumatologist if they still had knee pain and fulfilled the following criteria: pain for more than 6 weeks; insidious onset of knee pain felt anteriorly around the patella or diffusely around the knee; no treatment within the previous 12 months, and no previous knee surgery.

\section{Inclusion and exclusion criteria}

Eligibility criteria for inclusion were applied by the rheumatologist at the clinical exam, and were in line with a previous clinical trial [2] as follows:

1) Insidious onset of anterior knee or retropatellar pain of greater than 6 weeks' duration;

2) Pain provoked by at least two of the following situations: prolonged sitting or kneeling, squatting, running, hopping, or stair walking;

3) Tenderness on palpation of the patella, or pain with stepping down or double leg squatting;

4) Worst pain during the previous week of more than $30 \mathrm{~mm}$ on a $100 \mathrm{~mm}$ visual analogue scale (VAS).

Exclusion criteria were the following:

1) Concomitant injury or pain from the hip, lumbar spine, or other knee structures;

2) Previous knee surgery;

3) Patellofemoral instability;

4) Knee joint effusion;

5) Use of physiotherapy for treating knee pain within the previous year;

6) Weekly use of anti-inflammatory drugs.

\section{Intervention}

One physiotherapist delivered the multimodal intervention (patient education, exercise therapy and patella taping, Table 1) to all participants. She was previously involved in administering this intervention to older adolescents (15-19 years of age) with PFP [8]. The intervention was an exact replication of the intervention delivered in that RCT $[8,14]$. 
Table 1 TIDieR checklist for reporting of interventions

\begin{tabular}{|c|c|c|c|c|c|c|c|c|c|}
\hline $\begin{array}{l}\text { Intervention } \\
\text { name }\end{array}$ & Why & $\begin{array}{l}\text { What (materials } \\
\text { and procedure) }\end{array}$ & Who provided & How? & $\begin{array}{l}\text { Where did } \\
\text { the } \\
\text { intervention } \\
\text { take place }\end{array}$ & $\begin{array}{l}\text { When and } \\
\text { how much? }\end{array}$ & Tailoring & Modification & $\begin{array}{l}\text { How well? } \\
\text { (fidelity and } \\
\text { adherence) }\end{array}$ \\
\hline $\begin{array}{l}\text { Exercise } \\
\text { therapy and } \\
\text { patient } \\
\text { education }\end{array}$ & $\begin{array}{l}\text { This } \\
\text { multimodal } \\
\text { program } \\
\text { has never } \\
\text { been tested } \\
\text { in young } \\
\text { adolescents } \\
\text { with PFP, } \\
\text { only among } \\
15-19 \text { year } \\
\text { olds with } \\
\text { PFP. }\end{array}$ & $\begin{array}{l}\text { One } \\
\text { physiotherapist } \\
\text { delivered } \\
\text { the patient } \\
\text { education, } \\
\text { exercise } \\
\text { therapy, and } \\
\text { instructions on } \\
\text { patellar taping. } \\
\text { The exercise } \\
\text { therapy was } \\
\text { based on } \\
\text { previous trials } \\
\text { and consisted } \\
\text { of a combination } \\
\text { of supervised } \\
\text { group training } \\
\text { sessions and } \\
\text { unsupervised } \\
\text { home-based } \\
\text { exercises. }\end{array}$ & Physiotherapist & $\begin{array}{l}\text { Face } \\
\text { to } \\
\text { face }\end{array}$ & $\begin{array}{l}\text { At the } \\
\text { hospital }\end{array}$ & $\begin{array}{l}\text { The } \\
\text { unsupervised } \\
\text { home } \\
\text { exercises } \\
\text { consisted of } \\
\text { approximately } \\
15 \text { min of } \\
\text { quadriceps } \\
\text { and hip } \\
\text { muscle } \\
\text { retraining and } \\
\text { stretching and } \\
\text { were performed } \\
\text { every day } \\
\text { except for the } \\
\text { days of } \\
\text { supervised } \\
\text { sessions. The } \\
\text { supervised } \\
\text { exercises were } \\
\text { offered three } \\
\text { times per } \\
\text { week at the } \\
\text { hospital for } \\
13 \text { weeks. } \\
\text { Full description } \\
\text { of intervention } \\
\text { can be seen } \\
\text { in this open } \\
\text { access } \\
\text { publication [3] }\end{array}$ & $\begin{array}{l}\text { To } \\
\text { progressively } \\
\text { match the } \\
\text { exercise } \\
\text { level to the } \\
\text { performance } \\
\text { level and pain } \\
\text { levels of each } \\
\text { participant, } \\
\text { all exercises } \\
\text { were available } \\
\text { in multiple } \\
\text { levels of } \\
\text { difficulty. }\end{array}$ & $\begin{array}{l}\text { All adolescents } \\
\text { started with } \\
\text { exercises at } \\
\text { level } 1 \text { and } \\
\text { progressed } \\
\text { from there. The } \\
\text { progression } \\
\text { followed } \\
\text { previously } \\
\text { described rules. } \\
\text { (1) Good quality } \\
\text { of movement } \\
\text { determined by } \\
\text { the physiotherapist. } \\
\text { 'Good quality' is } \\
\text { defined as able } \\
\text { to control hip, } \\
\text { knee, and foot } \\
\text { alignment } \\
\text { during exercises } \\
\text { with both extra- } \\
\text { slow and } \\
\text { slightly faster } \\
\text { than normal } \\
\text { movement. } \\
\text { (2) Ability to } \\
\text { perform the } \\
\text { actual number } \\
\text { of repetitions } \\
\text { as defined in } \\
\text { the training } \\
\text { protocol. } \\
\text { (3) No self- } \\
\text { reported } \\
\text { increase in } \\
\text { usual pain after } \\
\text { the training } \\
\text { session or the } \\
\text { next morning. }\end{array}$ & $\begin{array}{l}\text { Adherence } \\
\text { to the } \\
\text { supervised } \\
\text { sessions was } \\
\text { recorded as } \\
\text { attendance. } \\
\text { The } \\
\text { adolescents } \\
\text { participated } \\
\text { in a median } \\
\text { of } 16 \\
\text { (IQR 5.5-25) } \\
\text { supervised } \\
\text { training } \\
\text { session } \\
\text { during the } \\
13 \text { weeks }\end{array}$ \\
\hline
\end{tabular}

\section{Patient education}

Patient education lasted for approximately $30 \mathrm{~min}$ and was standardised and covered the following topics: (1) why does it hurt, (2) pain management, (3) how to modify physical activity, (4) how to return slowly to sports, (5) how to cope with knee pain, (6) information on optimal knee alignment during sit-to-stand, standing, walking, stair walking and bicycling, and, (7) questions from the adolescent or the parents. Adolescents received information both face to face and in an 8-page leaflet.

\section{Exercise therapy}

Exercise therapy was delivered and supervised by one physiotherapist who had previous experience in treating PFP, and more than 3 years of practical experience with adolescents and group-based exercises. Group-based exercise sessions were offered at the local hospital three times per week. All exercises were available in three to four different levels to allow for tailoring to each adolescent's performance and to enable progression in load and difficulty (i.e. balance and control) of the exercises. Adolescents started at level one and progressed from there. Progression was made on three general rules:

(1) Good quality of movement (determined by the physiotherapist). This was defined as being able to control hip, knee, and foot alignment during exercises with both extra-slow and slightly faster than normal movement.

(2) Ability to perform the complete number of repetitions defined in the training protocol.

(3) No increase in usual pain after the training session or the next morning.

Further, the physiotherapist could adjust the external weight, repetitions, and sets based on pain. Generally, adolescents started with a load of 15 repetition maximum (RM), progressing to three sets of 8-10 RM. Adolescents 
were instructed to inform the physiotherapist if they felt their pain exceeded $3 \mathrm{~cm}$ on a Numeric Rating Scale (NRS), and the load was adjusted accordingly.

To account for variation in the time the school lessons end and improve adherence, students were offered the opportunity to attend the supervised group training session at 15:00 or 16:00. Group-based training sessions were available three times per week (Mondays, Wednesdays, and Fridays) for 3 months (corresponding to 13 weeks or a total of 39 training sessions).

\section{Patellar taping}

Patella taping was used if patients achieved a minimum of $50 \%$ reduction in pain (measured by VAS) during a two-leg squat immediately after application of tape. The patellar taping was based on the McConnell approach as it may reduce pain during exercise [12]. Non-rigid, hypoallergenic tape (Curafix H, Lohmann and Rauscher, Neuweid, Germany) was used to reduce skin irritation, while rigid zinc-oxide tape (Leuko P, BSN Medical, Hamburg, Germany) was applied to correct the position of the patella. Taping corrections were applied in a predetermined order of anterior tilt, medial tilt, glide, and fat pad unloading until the participant's pain was reduced by at least $50 \%$ [15]. If the taping did not reduce pain, participants were not instructed to use it. If the taping reduced pain, adolescents were taught to independently apply the taping corrections and instructed to reapply daily, and to wear it during waking hours for the duration of the intervention period.

\section{Home exercises}

In addition to the supervised group training, adolescents were instructed to perform home exercises four times per week. They were also instructed to perform home exercise if there were any days where they missed the supervised exercises. Home-based exercises consisted of quadriceps and hip muscle exercises, and stretching [8]. These were also included during the supervised exercise therapy to ensure adolescents were well instructed in the home exercises. Adolescents were advised to continue to perform home exercises after the 3 months of group-based exercises finished. No specific time-period was given.

\section{Adherence}

Parents were invited to participate in all aspects of the study, with a hope to optimise adherence to the intervention and increase retention. Communication was done through telephone or email. The day before appointments, adolescents were sent an SMS reminder. Participants were asked to send an SMS to the physiotherapist, if they could not participate in the group training sessions. If students did not show up for training twice in a row, without cancelling through SMS, they were telephoned by the physiotherapist who asked them in a friendly manner when they would return.

Adherence to supervised exercise therapy was recorded as attendance at the supervised classes. The physiotherapist recorded participation in the group-based exercises at each session. We defined good adherence as participation in at least $80 \%$ of the supervised group training sessions, as was previously used in adolescents with PFP [8]. Poor adherence was defined as participation in less than $40 \%$ of the group training sessions [8]. Adherence to the homebased exercises were based on self-report data from a training $\log$ from the adolescents.

\section{Concurrent interventions}

Adolescents were asked to refrain from other interventions during the intervention period, starting $72 \mathrm{~h}$ before participation in the study. Pre-existing foot orthoses were allowed, but they were not allowed to change or modify their current orthoses during the study period. Current or prior analgesic use for the current knee pain was registered during baseline testing and all follow-ups. However, we note the small sample size, and these results should be interpreted with caution.

\section{Outcome measurements}

Adolescents filled in self-report questionnaires at baseline, 3 , and 6 months. The questionnaires were trialled successfully among a small group of 3-5 adolescents before we used them in the current study.

A priori, we defined that our primary measures of interest were adherence to the intervention, and the number of adolescents with a successful outcome. We deemed these two measures relevant to inform feasibility and sample size requirements for a potential future trial. Successful outcome was measured on a 7-point Likert scale ranging from "completely recovered" to "worse than ever". Identical to van Linschoten et al. patients were categorised as having a successful outcome if they rated themselves as "fully recovered" or "strongly recovered", whereas those who rated themselves as "slightly recovered" to "worse than ever" were categorised as not having a successful outcome [16]. Other outcomes were the Knee injury and Osteoarthritis Outcome Score (KOOS) [17], physical activity scale (PAS) [18], and weekly sports participation (number of times per week). Health-related quality of life was measured by the European Quality of Life 5 dimensions Youth (EQ-5DY) [19]. Worst pain during the past week and pain during usual activity were measured on a visual analogue scale (VAS). Treatment was measured on a 5-point Likert scale ranging from "highly satisfied" to "not satisfied at all". Adolescents were allowed ask their parents if they were unsure about the meaning of the questions. 
In addition to the self-report outcomes, isometric strength was measured before and after the 3-month intervention. The testing setup included a portable dynamometer and an examination table as described in our previous described methods [20]. Muscle strength was tested with the Mecmesin AFG2500 dynamometer, which was bolted to the wall to ensure fixation. All strength tests were tested isometrically. Six movement directions around the knee and hip were tested as follows: knee flexion and extension; hip abduction and adduction; hip internal and external rotation. The dynamometer strap was positioned $5 \mathrm{~cm}$ proximal to the medial malleolus, perpendicular to the anterior or posterior aspect of the tibia [20]. Knee extension strength was tested with the knee in $60^{\circ}$ flexion, while flexion strength was tested during $90^{\circ}$ of knee flexion. Hip abduction and adduction were tested with the participant lying supine on the examination table. The strap was positioned $5 \mathrm{~cm}$ proximal to the medial malleolus, perpendicular to the medial or lateral aspect of the tibia. The leg was placed in $0^{\circ}$ flexion and abduction. Hip internal and external rotation strength were tested with the participant sitting on one side of the examination table, with the hip and knee flexed at $90^{\circ}$. The reliability of these tests was high, with ICC values for all six movement directions were above 0.92 [20].

\section{Sample size}

As this was a pilot study, no formal sample size calculation was undertaken. Twenty adolescents were included to inform a proper sample size calculation for a future trial from the data on the adherence to the exercise intervention, and the results from the 7-point Likert scale (ranging from "highly satisfied" to "not satisfied at all").

\section{Statistical analysis}

All data were visually inspected for normality using a Q-Q plot. Mean values \pm SD are reported if data were normally distributed. If data were non-normally distributed, they were presented as median and interquartile range (IQR). Paired samples $t$ tests were used to test the changes in patient reported outcomes and isometric strength between matched pairs. Mann-Whitney $U$ tests were used to compare adherence to home-based exercises between adolescents with good and poor adherence to supervised exercises. $P<0.05$ was considered statistically significant. All calculations were performed using Stata version 11 (StataCorp, College Station, TX, USA).

\section{Results}

\section{Participants}

Twenty adolescents between 12 and 16 years of age were included (Table 2). Eighteen of these 20 adolescents participated in the follow-up after 3 months and 18 of the 20 participated in the follow-up at 6 months. Ten
Table 2 Participant characteristics

\begin{tabular}{ll}
\hline & $\begin{array}{l}\text { Adolescents with PFP } \\
N=20\end{array}$ \\
\hline Age [years] & $14.6( \pm 1.1)$ \\
Height $[\mathrm{cm}]$ & $167.0( \pm 10.0)$ \\
Weight $[\mathrm{kg}]$ & $55.2( \pm 9.0)$ \\
Gender (number of females) & 16 \\
BMI [kg/m²] & $19.5(18.2-20.7)^{* *}$ \\
Pain duration [months] & $28.5(24-36)^{* *}$ \\
Sports participation [times per week] & $4(3-4.5)^{* *}$ \\
Regular use of pain killers (number & 11 \\
of adolescents) & \\
\hline
\end{tabular}

The variables are presented as mean and standard deviation or median and inter-quartile range. $B M I$ body mass index

**Presented as median and interquartile range

adolescents responded to patellar taping and were advised to continue using it throughout the 13 weeks.

\section{Adherence}

Adolescents participated in a median of 16 (IQR 5.5-25) supervised training session during the 13 weeks (Fig. 1). None participated in more than $80 \%$ of the 39 supervised training sessions, with $40 \%$ participating in less than $40 \%$ (therefore, being characterised as having poor adherence). At least one parent of each child took part in the education session, but no parents took part in the supervised exercise sessions despite being invited.

During the first 3 months, adolescents reported performing a median of 2 (IQR 2-3) home training sessions per week, with a median of 26 home-based training sessions over the course of the 13 weeks (corresponding to $50 \%$ of the prescribed home exercise dosage). Adolescents with poor adherence to supervised training reported a slightly higher adherence to home-based exercises compared to compliant adolescents (3 (IQR 3-4) vs 2 (IQR 2-2) times per week; $p=0.002$ ), corresponding to $75 \%$ of the prescribed home exercise dosage. Six adolescents reported still performing their home exercises at 6 month follow-up (median of 2.5 times per week (IQR 2-3)), while the rest reported that they had stopped.

\section{Recovery, satisfaction with the treatment and co- interventions}

Five adolescents were categorised as having a successful outcome after 3 months. Similarly, 5/18 adolescents had a successful outcome after 6 months (only three of these had a successful outcome at both time-points). Eleven out of 18 reported being highly satisfied or very satisfied with the results of the treatment after 3 months. Nine out of 18 were either highly satisfied or very satisfied with the results of the treatment after 6 months. There were only small improvements in self-reported outcomes (Table 3). 


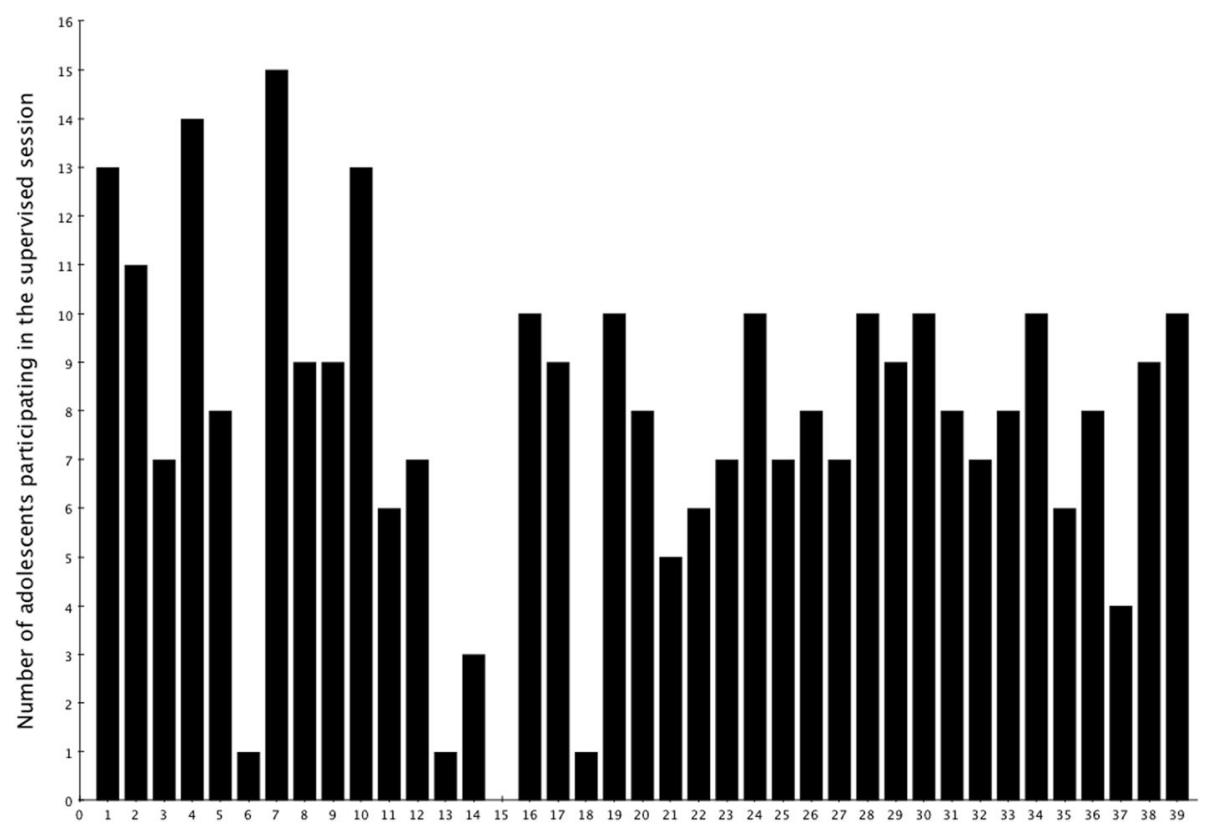

Fig. 1 Adherence during the 3 months. In total, adolescents were offered to attend 39 supervised training sessions

\section{Isometric muscle strength}

There were no significant changes in knee strength from before to after the 3-month intervention. While there were some small significant changes in hip strength, these did not exceed previously established limits of agreement for hip strength (Table 4).

\section{Concurrent interventions}

One adolescent reported "acupuncture" and one adolescent visited a physiotherapist outside the study, during the 13 weeks of intervention. Two adolescents reported visiting a physiotherapist between the 3 and 6 months follow-up.
Nine adolescents used pain-killers at 3 months follow-up, and 11 used pain-killers at 6 months follow-up.

\section{Discussion}

Our primary measures of interest were adherence to, and the clinical effects of, exercise therapy and patient education in young adolescents with PFP. Due to the shorter symptom duration compared to our previous trial in older adolescents [2], we expected the intervention would have a stronger effect in this young adolescent population. Contrary to this, the intervention demonstrated

Table 3 Patient-reported outcome measures and physical activity level

\begin{tabular}{|c|c|c|c|c|c|c|}
\hline & $\begin{array}{l}\text { Baseline } \\
( \pm \text { SD) }\end{array}$ & $\begin{array}{l}\text { 3-month } \\
\text { follow-up } \\
( \pm \text { SD) }\end{array}$ & $\begin{array}{l}\text { 6-month } \\
\text { follow-up } \\
( \pm \text { SD) }\end{array}$ & $\begin{array}{l}\text { Mean change } \\
\text { from baseline to } \\
3 \text { months ( } 95 \% \text { Cl) }\end{array}$ & $\begin{array}{l}\text { Mean change } \\
\text { from } 3 \text { to } \\
6 \text { months }(95 \% \text { Cl) }\end{array}$ & $\begin{array}{l}\text { Mean change } \\
\text { from baseline to } \\
6 \text { months ( } 95 \% \text { Cl) }\end{array}$ \\
\hline KOOS pain & $71( \pm 13)$ & $70( \pm 16)$ & $76( \pm 14)$ & $1(-8 ; 9)$ & $6(-1 ; 10)$ & $5(-2 ; 11)$ \\
\hline KOOS symptom & $76( \pm 11)$ & $77( \pm 12)$ & $81( \pm 11)$ & $0(-7 ; 6)$ & $4(-1 ; 7)$ & $5(-2 ; 11)$ \\
\hline KOOS activities of daily living & $79( \pm 13)$ & $82( \pm 14)$ & $87( \pm 10)$ & $2(-5 ; 9)$ & $5(0 ; 9)$ & $7(0 ; 13)$ \\
\hline KOOS sport and recreation & $58( \pm 19)$ & $62( \pm 21)$ & $68( \pm 21)$ & $4(-7 ; 14)$ & $6(-4 ; 16)$ & $9(1 ; 18)$ \\
\hline KOOS quality of life & $54( \pm 12)$ & $59( \pm 21)$ & $59( \pm 21)$ & $4(-4 ; 11)$ & $0(-10 ; 10)$ & $4(-4 ; 12)$ \\
\hline $\begin{array}{l}\text { Physical activity level (physical activity } \\
\text { scale (METs)) }\end{array}$ & $45.0( \pm 8.3)$ & $49.4( \pm 10.7)$ & $55.4( \pm 13.0)$ & $4.8(-1.8 ; 11.3)$ & $6.2(-1.1 ; 13.6)$ & $10(2 ; 19)$ \\
\hline Health-related quality of life (EQ5D index**) & $0.75(0.72-0.78)$ & $0.78(0.72-0.82)$ & $0.82(0.72 ; 0.84)$ & & & \\
\hline Self-related health (EQ-VAS) & $76( \pm 22)$ & $78( \pm 15)$ & $78( \pm 17)$ & $-1(-8 ; 9)$ & $0(-8 ; 8)$ & $1(-8 ; 6)$ \\
\hline Worst pain last week (VAS* worst) & $62( \pm 19)$ & $51( \pm 27)$ & $48( \pm 27)$ & $-10(-22 ; 3)$ & $-3(-14 ; 8)$ & $-13(-27 ; 1)$ \\
\hline Pain during activity (VAS* activity) & $56( \pm 19)$ & $37( \pm 26)$ & $37( \pm 22)$ & $-18(-30 ; 6)$ & $-1(-7 ; 5)$ & $-19(-30 ;-8)$ \\
\hline
\end{tabular}

*VAS visual analogue scale

**Reported as median and interquartile range 
Table 4 Isometric muscle strength at baseline and 3-month follow-up

\begin{tabular}{|c|c|c|c|c|}
\hline & Baseline $( \pm \mathrm{SD})$ & Follow-up at 3 months $( \pm S D)$ & Difference $(95 \% \mathrm{Cl})$ & $p$ value \\
\hline Knee extension (\%BW) & $0.82( \pm 0.21)$ & $0.84( \pm 0.23)$ & $0.01(-0.04 ; 0.06)$ & 0.59 \\
\hline Knee flexion (\%BW) & $0.33( \pm 0.07)$ & $0.33( \pm 0.07)$ & $0.01(-0.02 ; 0.03)$ & 0.63 \\
\hline Hip abduction (\%BW) & $0.26( \pm 0.05)$ & $0.24( \pm 0.05)$ & $-0.02(-0.03 ; 0.00)$ & 0.03 \\
\hline Hip adduction (\%BW) & $0.27( \pm 0.07)$ & $0.24( \pm 0.05)$ & $-0.03(-0.05 ;-0.01)$ & 0.01 \\
\hline Hip external rotation (\%BW) & $0.21( \pm 0.04)$ & $0.23( \pm 0.05)$ & $0.01(0.00 ; 0.02)$ & 0.05 \\
\hline Hip internal rotation (\%BW) & $0.32( \pm 0.06)$ & $0.34( \pm 0.07)$ & $0.02(0.00 ; 0.04)$ & 0.09 \\
\hline
\end{tabular}

no clear effect, with low adherence to the intervention, and little involvement from the parents.

As with older adolescents $[8,21]$, adherence to supervised exercise therapy was low, with $40 \%$ attending less than $40 \%$ of all supervised training sessions, and none being classified as having good adherence (partaking in $>80 \%$ of training sessions). Over the 13-week intervention, participants attended a median of 18 supervised training sessions (compared to 8.5 in the previous RCT in older adolescents [8]), and 26 home-based training sessions. Despite similar (if not slightly higher) adherence, the proportion of successful outcomes at 6 months seemed slightly lower in this pilot study. Considering the poor adherence and clinical effects, this suggests that supervised exercises offered three times per week for 3 months may not be optimal for this age group. The adolescents reported participating in a higher number of home-based unsupervised training session compared to their participation in supervised training sessions. This suggests that home-based intervention may result in better adherence in this young population. This would potentially be preferable due to its less time intensive nature, lower cost, and ease of implementation. Recent research suggests the environment contributes to treatment response [22]. As such, matching patients' preferences to treatment rooms may be a way to improve outcome and adherence [22]. Future studies need to explore the reasons for poor adherence, and if/how interventions may be better tailored to adolescents' preferences to improve adherence.

Unfortunately, the intervention did not improve hip or knee strength, despite its previous efficacy in older adolescents with PFP [23]. This could be due to the previously mentioned problems with compliance. On the other hand, it has been shown that younger adolescents with PFP do not yet display similar strength deficits [20] as older adolescents (age 15-19) [20] and adults with PFP [24]. One study even demonstrated that increased hip strength was a risk factor for PFP in adolescent females [25]. An important consideration is that, PFP is often associated with high sports participation, with one in four adolescent female athletes suffering from it [26]. The adolescents in this study still participated in sport on average, four times per week despite long-standing knee pain, and may not yet have developed strength deficits due to absence from their sport. If these young adolescents had not yet developed strength deficits, this may explain why strength training was not as effective in this population. As previous research indicates that individuals with the largest strength deficits benefit most from exercise therapy [27], there is no strong rationale for focussing solely on exercise therapy and strength improvements in this population.

Participants in this cohort had an average pain duration of 28 months, despite their young age. As pain duration is one of the most consistent predictors of poor outcome [10], there is a need to identify better treatment strategies to intervene in young adolescents with early onset of PFP. It has previously been highlighted that there is a difference in the responsiveness of adolescents and adults with PFP to exercise therapy, despite similar exercise adherence [9]. Current exercise-focused treatments are only effective for $30-40 \%$ of adolescents (15-19 years of age) with PFP [8]. One of the plausible reasons for lack of effectiveness is that exercise therapy, on its own, does not help the adolescents modify and control their sports participation. Our previous research demonstrates that adolescents with PFP continue to participate in high-level sports despite long-standing and intense knee pain. One solution may be to investigate activity modification and load management to teach the adolescent how to modify and control their sports participation based on their knee symptoms.

Currently, there is a lack of research examining management of PFP [1] in adolescents, despite the fact that it is the most common and persistent knee condition seen in this population [8, 28]. One previous RCT, using the same comprehensive intervention as the current investigation, demonstrated that less than $40 \%$ had a successful outcome after 1 year. Taking the poor adherence in this pilot study together with this underscores the need for better tailored management strategies for this young population. Future studies need to explore interventions that can obtain good adherence, engage parents to reinforce adherence, and include activity modification and load management. We believe these steps will be vital to address in order to develop optimal intervention strategies specifically tailored to the lives and needs of adolescents. 


\section{Limitations}

This was a pilot study on a small cohort of young adolescents with PFP. There was no control group preventing us from understanding this intervention compared to other treatment strategies. The patientreported outcomes were supposed to be used to inform a sample size calculation for a full clinical trial. However, adherence to the intervention was poor, and there were only small clinical effects of the intervention, making a full clinical trial impractical. Additionally, as we did not measure physical activity levels throughout the study with objective methods such as accelerometer, it is unknown how physical activity changed during the study or if this is associated with successful outcomes.

\section{Conclusion}

This was the first study to investigate adherence to, and clinical effects of, patient education and exercise therapy in young adolescents with PFP. Adherence was low, as was the clinical effect from this approach. This suggests that supervised exercises three times per week after school hours are not optimal in this population. It therefore seems important to develop new and better strategies for adolescents with PFP. One approach could include load management and more patient empowerment on how the adolescents can manage their pain and sports participation at home to help them return safely to their sports.

\section{Acknowledgements}

Thanks to the adolescents and parents for taking part in the research.

\section{Availability of data and materials}

De-identified individual-patient data are available by contacting the corresponding author.

\section{Authors' contributions}

MSR designed the study, helped in the acquisition and interpretation of data, and drafted the first version of the manuscript. CRR designed the study, helped in the acquisition and interpretation of data, revised the manuscript for intellectual content, and read and approved the final manuscript. SH and $K T$ contributed to the interpretation of data, revised the manuscript for intellectual content, and read and approved final manuscript. JLO designed the study, helped in the acquisition and interpretation of data, revised the manuscript for intellectual content, and read and approved final manuscript.

\section{Ethics approval and consent to participate}

The local ethics committee of North Denmark Region approved the study (2011-0200). All participants were required to give written informed consent accompanied by their parents' consent. The study was conducted according to the Declaration of Helsinki.

\section{Consent for publication}

The manuscript does not contain data from any individual person in a form that could be offensive to anyone but written informed consent for all patients was collected.

\section{Competing interests}

The authors declare that they have no competing interests.

\section{Publisher's Note}

Springer Nature remains neutral with regard to jurisdictional claims in published maps and institutional affiliations.

\section{Author details}

${ }^{1}$ Research Unit for General Practice, Department of Clinical Medicine, Aalborg University, Aalborg, Denmark. ${ }^{2}$ Department of Occupational Therapy and Physiotherapy, Department of Clinical Medicine, Aalborg University Hospital, Aalborg, Denmark. ${ }^{3}$ Sports Orthopedic Research Center-Copenhagen (SORC-C), Department of Orthopedic Surgery, Copenhagen University Hospital, Hvidovre, Denmark. ${ }^{4}$ Institute of Sports Medicine Copenhagen, Copenhagen University Hospital, Bispebjerg, Denmark.

Received: 24 February 2017 Accepted: 22 December 2017

Published online: 13 April 2018

\section{References}

1. Rathleff MS. Patellofemoral pain during adolescence: much more prevalent than appreciated. Br J Sports Med. 2016;50:831-2.

2. Bjerrum L, Ertmann RP, Jarbøl DE, Jensen MB, Kristensen JK, Maagaard R. Almen Medicin. 1st ed. Danmark: Munksgaard; 2014.

3. Mølgaard C, Rathleff MS, Simonsen $\mathrm{OH}$. Patellofemoral pain syndrome and its association with hip, ankle, and foot function in 16- to 18-year-old high school students. J Am Podiatr Med Assoc. 2011;101:215-22.

4. Smith BE, Moffatt F, Hendrick P, Bateman M, Rathleff MS, Selfe J, Smith TO, Logan $P$. The experience of living with patellofemoral pain-loss, confusion and fear-avoidance: a UK qualitative study. BMJ Open. 2018;8(1):e018624 http://journals.plos.org/plosone/article?id=10.1371/journal.pone.0190892.

5. Rathleff MS, Roos EM, Olesen JL, Rasmussen S, Arendt-Nielsen L. Lower mechanical pressure pain thresholds in female adolescents with patellofemoral pain syndrome. J Orthop Sports Phys Ther. 2013;43:414-21.

6. van der Heijden RA, Lankhorst NE, van Linschoten R, Bierma-Zeinstra SMA van Middelkoop M. Exercise for treating patellofemoral pain syndrome. Cochrane Database Syst Rev. 2015;1:CD010387.

7. Barton CJ, Lack S, Hemmings S, Tufail S, Morrissey D. The "best practice guide to conservative management of patellofemoral pain": incorporating level 1 evidence with expert clinical reasoning. Br J Sports Med. 2015;49:923-34.

8. Rathleff MS, Roos EM, Olesen JL, Rasmussen S. Exercise during school hours when added to patient education improves outcome for 2 years in adolescent patellofemoral pain: a cluster randomised trial. Br J Sports Med. 2015;49:406-12.

9. Rathleff MS, Vicenzino B, Middelkoop M, Graven-Nielsen T, van Linschoten R, Hölmich P, et al. Patellofemoral pain in adolescence and adulthood: same same, but different? Sports Med. 2015;45:1489-95.

10. Matthews M, Rathleff MS, Claus A, McPoil T, Nee R, Crossley K, et al. Can we predict the outcome for people with patellofemoral pain? A systematic review on prognostic factors and treatment effect modifiers. Br J Sports Med. 2017; 51(23):1650-60.

11. Rathleff MS, Roos EM, Olesen JL, Rasmussen S. High prevalence of daily and multi-site pain-a cross-sectional population-based study among 3000 Danish adolescents. BMC Pediatr. 2013;13:191.

12. Elm von E, Altman DG, Egger M, Pocock SJ, Gøtzsche PC, Vandenbroucke $J P$, et al. The strengthening the reporting of observational studies in epidemiology (STROBE) statement: guidelines for reporting observational studies. J Clin Epidemiol. 2008:61:344-9.

13. Hoffmann TC, Glasziou PP, Boutron I, Milne R, Perera R, Moher D, et al. Better reporting of interventions: template for intervention description and replication (TIDieR) checklist and guide. BMJ. 2014;348:g1687.

14. Rathleff MS, Roos EM, Olesen JL, Rasmussen S. Early intervention for adolescents with patellofemoral pain syndrome-a pragmatic cluster randomised controlled trial. BMC Musculoskelet Disord. 2012;13:9.

15. Crossley K, Bennell K, Green S, Cowan S, McConnell J. Physical therapy for patellofemoral pain: a randomized, double-blinded, placebo-controlled trial. Am J Sports Med. 2002;30:857-65.

16. van Linschoten $R$, van Middelkoop M, Berger MY, Heintjes EM, Verhaar JAN, Willemsen SP, et al. Supervised exercise therapy versus usual care for patellofemoral pain syndrome: an open label randomised controlled trial. BMJ. 2009:339:b4074.

17. Roos EM, Lohmander LS. The knee injury and osteoarthritis outcome score (KOOS): from joint injury to osteoarthritis. Health Qual Life Outcomes. 2003;1:64. 
18. Aadahl M, Jørgensen T. Validation of a new self-report instrument for measuring physical activity. Med Sci Sports Exerc. 2003;35:1196-202.

19. Burström K, Egmar A-C, Lugnér A, Eriksson M, Svartengren M. A Swedish child-friendly pilot version of the EQ-5D instrument-the development process. Eur J Pub Health. 2011;21:171-7.

20. Rathleff CR, Baird WN, Olesen JL, Roos EM, Rasmussen S, Rathleff MS. Hip and knee strength is not affected in 12-16 year old adolescents with patellofemoral pain-a cross-sectional population-based study. PLoS One. 2013;8:e79153.

21. Rathleff MS, Bandholm T, McGirr KA, Harring SI, Sørensen AS, Thorborg K. New exercise-integrated technology can monitor the dosage and quality of exercise performed against an elastic resistance band by adolescents with patellofemoral pain: an observational study. J Physiother. 2016;62:159-63.

22. Sandal LF, Thorlund JB, Moore AJ, Ulrich RS, Dieppe PA, Roos EM. Room for improvement: a randomised controlled trial with nested qualitative interviews on space, place and treatment delivery. Br J Sports Med. 2017; https://doi.org/10.1136/bjsports-2016-097448. [Epub ahead of print].

23. Rathleff MS, Samani A, Olesen JL, Roos EM, Rasmussen S, Madeleine P. Effect of exercise therapy on neuromuscular activity and knee strength in female adolescents with patellofemoral pain-an ancillary analysis of a cluster randomized trial. Clin Biomech (Bristol, Avon). 2016;34:22-9.

24. Rathleff MS, Rathleff CR, Crossley KM, Barton CJ. Is hip strength a risk factor for patellofemoral pain? A systematic review and meta-analysis. Br J Sports Med. 2014;48:1088

25. Herbst KA, Barber Foss KD, Fader L, Hewett TE, Witvrouw E, Stanfield D, et al. Hip strength is greater in athletes who subsequently develop patellofemoral pain. Am J Sports Med. 2015;43:2747-52.

26. Barber Foss KD, Myer GD, Chen SS, Hewett TE. Expected prevalence from the differential diagnosis of anterior knee pain in adolescent female athletes during preparticipation screening. J Athl Train. 2012;47:519-24.

27. Pattyn E, Mahieu N, Selfe J, Verdonk P, Steyaert A, Witvrouw E. What predicts functional outcome after treatment for patellofemoral pain? Med Sci Sports Exerc. 2012:44:1827-33.

28. Rathleff MS, Rathleff CR, Olesen JL, Rasmussen S, Roos EM. Is knee pain during adolescence a self-limiting condition? Prognosis of patellofemoral pain and other types of knee pain. Am J Sports Med. 2016;44:1165-71.

\section{Submit your next manuscript to BioMed Central and we will help you at every step:}

- We accept pre-submission inquiries

- Our selector tool helps you to find the most relevant journal

- We provide round the clock customer support

- Convenient online submission

- Thorough peer review

- Inclusion in PubMed and all major indexing services

- Maximum visibility for your research

Submit your manuscript at wuw biomedcentral.com/submit

C Biomed Central 